\title{
Antirealism and the Roles of Truth
}

Sundholm, B.G.; Niniluoto I, Sintonen M

\section{Citation}

Sundholm, B. G. (2004). Antirealism and the Roles of Truth. In S. M. Niniluoto I (Ed.), Handbook of Epistemology (pp. 437-466). Dordrecht: Kluwer. Retrieved from https://hdl.handle.net/1887/12024

Version: $\quad$ Not Applicable (or Unknown)

License: $\quad$ Leiden University Non-exclusive license

Downloaded from: https://hdl.handle.net/1887/12024

Note: To cite this publication please use the final published version (if applicable). 


\section{GÖRAN SUNDHOLM}

\section{ANTIREALISM AND THE ROLES OF TRUTH}

The position indicated by the term "antirealism" has come to the fore in philosophical discussion during the last thirty years, largely as a result of the writings of Michael Dummett.' Prima facie one would expect an antirealist critique of realism to comprise two parts: a negative part (as the name indicates) criticising the realist view, and a positive part setting out a constructive alternative to the realist position. The tradition starting with Dummett, it is fair to say, has mainly been concerned with the negative part of antirealism. Here, however, the antirealist appears to have a large, and definite, disadvantage in his perennial discussion with the realist, purely in virtue of the chosen label; his position is laid down negatively in opposition to a prior realist position. Accordingly, the antirealist's campaign will be fought on a field determined by his opponent, and in terms chosen by him. Therefore, in this Chapter, I do not take the views of Dummett as my point of departure, especially since the need for a survey of antirealism from this perspective has been excellently met by Hale (1997). Furthermore, in a Handbook of Epistemology, this manner of proceeding (that is, not taking Dummett's views as the point of departure) is quite appropriate, since one of Dummett's main tenets is the primacy of the theory of meaning over the theory of knowledge. Instead, I discuss a number of traditional epistemological notions and theories from an antirealist standpoint, and I also treat of the early work in modern mathematical intuitionism that provided the inspiration for much of the current work on semantical antirealism. Thus the present Chapter can be seen as providing an epistemological and philosophico-mathematical background to the modern semantical versions of antirealism.

\section{THE ROLES OF TRUTH IN RELATION TO THE TRADITIONAL THEORIES OF TRUTH}

Dummett famously recasts the debate between realism and idealism as a semantical dispute concerning the form that a proper theory of meaning has to take, and, in particular, what role has to be played by the notion of truth in such a theory. However, independently of these specific Dummettian concerns, it is clear that truth does have a major semantical role to play: after Frege and Wittgenstein many hold it to be a truism that

the meaning of a declarative sentence is given by, or in terms of, its truthcondition. $^{2}$

This semantical office, however, is not the only one in which truth has to serve; an equally important epistemological role for truth is given by a similar truism: 
what is known has to be true.

Finally, a third, metaphysical role of truth, so firmly stressed by Frege in the preface to his Grundgesetze, is that of making objectivity possible:

really being true is conceptually different from appearing to be true, that is, the distinction between appearance and reality must be upheld.

In view of their truistic character, an account of truth, meaning and knowledge that respects these platitudes is, ceteris paribus, preferable to an account that does not, and one would certainly expect a correct account to throw light on why the maxims in question have been considered truistic.

The epistemological tradition knows various so called theories of truth. What these traditional theories offer are general conceptions of truth; in the modern jargon they are theories of truth, that is, of, or about, the concept of truth, but they are not (Tarskian) truth theories that tell us under what condition the sentences of a certain language are true. These general conceptions of truth turn out to be admirably geared towards various offices as given by the above truisms. Thus, for instance, the evidence theory of truth, according to which what is true is what can be made evident (that is, known), caters very well for the epistemological role. ${ }^{3}$ Indeed, on this evidence-theoretical reading the maxim

what is known has to be true

becomes

what is known (what has been justified, warranted, made evident, etc.) has to be true (justifiable, warrantable, evidenceable, knowable, etc.),

and this is a priori obvious from the ab esse ad posse principle: what has already been done is certainly doable. ${ }^{4}$

Similarly, the traditional correspondence theory considers certain truth-bearers, be they judgements in the mind, or declarative sentences in the language, or propositions in the third realm of abstract entities, and relates these to appropriate truth-makers in the world:

a truth-bearer is true if a corresponding truth-maker exists.

When the truth-bearers are sentences, this maxim provides just the sort of languageworld link required for the semantical role of truth.

Finally, the metaphysical role of truth is catered for by the pragmatic and coherence theories of truth. The main task for the notion of truth when serving in this office (and perhaps even in general) is to hold open the possibility of making mistakes, that is, to rule out epistemological nihilism, by which I mean an epistemological counterpart to moral nihilism. This ethical position is characterised by the maxim 
'If God is dead, everything is permitted'.

The (contraposition of the) corresponding epistemological maxim is

'If mistakes are possible, then there is a norm of rightness'.

Another way of characterising epistemological nihilism is via the Homo mensura thesis of Protagoras:

Man is the measure of things.

If that be so, there is no difference between how things-seem-for-me and how they are, and mistakes are accordingly ruled out. The normative notion of rightness allows for an absolute distinction between appearance and reality and makes room for mistakes: a mistake is an act of knowledge that is not right. It is at issue in examples such as

I thought that he was a friend, but he turned out not to be a true friend.

In the Netherlands there is butter (known elsewhere as margarine) and real (or true)"cream" butter.

For many years Kummer's "proof" or the Four Colour Theorem was accepted, but in the end it was rejected as invalid. It was not a true proof.

This type of truth - "truth of things" - is known in scholastic philosophy as rectitudo ${ }^{6}$ Now, when a mistake is discovered, or suspected, at least one act of knowing (that is, of getting to know) cannot be right. Accordingly, one act, at least, will have to be annulled. The coherence and pragmatist theories of truth provide criteria for how to choose among the candidates for annulment: clearly an epistemological act that issues in a result that does not cohere with the body of knowledge is a strong candidate for annulment. Similarly, deeds with results that do not work, or are otherwise of no use, will be annulled. The above discussion can be summarised in a schema:

TRADITIONAL TRUTH THEORIES AND THE ROLES OF TRUTH
Truth according to the $\begin{aligned} & \text { Correspondence Theory Evidence Theory } \\ & \text { Eoherence and Pragmatic Theories }\end{aligned}$ caters for the $\begin{aligned} & \text { semantical } \\ & \text { epistemological } \\ & \text { metaphysical }\end{aligned}$

\section{ACTS AND OBJECTS}

In his characterisation of the realism/idealism ("antirealism") debate Fichte noted that basically there are only two epistemological options. ${ }^{7}$ The positions may be formulated in terms of the act/object dichotomy: 
object

Either you determine the object of knowledge as the object of the act, and then you are an idealist, or you determine the act in terms of a prior object towards which the act is directed, and then you are a realist (or "dogmatist", as Fichte said, being an idealist himself) ${ }^{8}$ If Fichte is right in this (and I suspect he is), the point is moot whether there is a neutral background position from which the issue between the realists and idealists can be adjudicated. For Fichte, it is clear that there is not. If this be so, it would serve to explain why the realism/idealism debate so often makes a futile impression; in place of a clear-cut decision, we find endless refinements of positions into sterile scholasticism, and conversions from one side to the other rarely take place. Brentano, Husserl, and Putnam are examples that spring to mind, all of whom came to reject their original realist stance. ${ }^{9}$ Moore and Russell, on the other hand, it is well-known, converted to realism from a prior adherence to British idealism.

It should be noted that, traditionally, the act through which we gain knowledge can be either mediate or immediate. The object of an immediate act is intuitive, or non-discursive, knowledge, that is, an axiom, but not in the current Hilbertian hypothetico-deductive sense: the axiomatic objects of immediate acts are selfevident truths, which neither need nor are capable of further demonstration. The axiom is evident in itself: knowledge of its terms and composition suffices for knowing its truth. In the scholastic terminology the axiom is a propositio per se nota, whose evidence is ex vi terminorum, that is, in virtue of the terms (concepts) out of which it is composed. ${ }^{10}$ "Meaning is what essence becomes when it is divorced from the object of reference and wedded to the word', quips Quine. Hence, after the so called linguistic turn, one often says that axioms are analytic, in the sense that they are 'true by virtue of meaning and independently of fact'. ${ }^{11}$ In fact, owing to a prevalent conventionalist view of meaning, axioms are even held to be conventions.

A mediate act of knowledge, on the other hand, is nothing but an act of inference in which one draws the conclusion $\mathrm{J}$ from the known premises $\mathrm{J}_{1}, \ldots, \mathrm{J}_{\mathrm{k}}$. This act thus makes use of the mode of inference I:

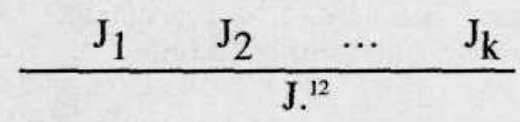

The appropriate notion of correctness for such (modes of) inference is that of validity. A mediate act of knowledge according to the mode of inference I takes the form (where the $J_{1}, \ldots, J_{k}$ are the objects of prior acts of knowledge):

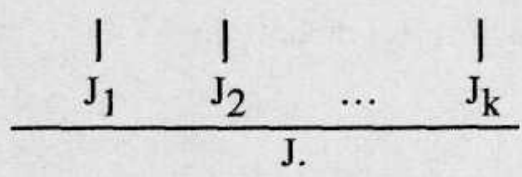


'This disambiguation between the two readings of 'inference', namely, mediate act of judgement versus mode of inference, raises the question of the relation between the corresponding notions of correctness: acts of inference have to be right, whereas inference-modes have to be valid. How, if at all, do these notions relate to each other? Clearly, in a right mediate act of knowing, every axiom used must be really (truly) evident, and every inference-mode that has been applied must be really valid. Thus, the task remains of elucidating the validity of inferences. Below I shall treat of both realist and anti-realist criteria for inferential validity.

In the present Chapter I intend to explore antirealism from this act/object perspective. I shall canvas a series of positions and pay attention to the above truisms on truth, as well as to the traditional theories of truth and their proper place, if any, within the particular anti-realist framework that I am concerned to develop here. Throughout I am indebted to the example offered by Per Martin-Löf in the philosophical explanations of his constructive theory of types. ${ }^{13}$ Taken together they constitute the only substantial anti-realist theory of meaning that has been developed so far.

\section{TRUTH-BEARERS AND THE FORM OF JUDGEMENT.}

A knowledge claim is commonly made through an assertion, that is, an assertoric utterance of a declarative sentence. For instance, by uttering the declarative

Snow is white

assertorically, I assert that snow is white. An assertoric utterance of (1) makes no explicit knowledge claim, but the assertion made, nevertheless, comprises an implicit such claim. This can be seen from the fact that one is entitled to counter an assertion with a demand for the grounds upon which the assertion rests: once the assertion has been made, the "asserter" is obliged, when challenged, to provide answers to counter-questions such as

How do you know this?

How do you know that snow is white?

Thus, incorporating the implicit claim to knowledge, the explicit form of the assertion made through an (assertoric) utterance of the declarative (1) is

I know that snow is white. ${ }^{14}$

The assertion by means of (1), when understood in the sense of (3), might be called a performative knowledge claim, as opposed to a propositional one. ${ }^{15}$

An utterance of the declarative (1) suffices to effect the assertion that snow is white, but an utterance, on the other hand, of the propositional nominalization 
does not so suffice. In order to obtain an expression with which the assertion in question can be effected through a single assertoric utterance, however, it is enough to augment (4) into

that snow is white is true

or, equivalently,

it is true that snow is white. ${ }^{16}$

If the knowledge claim (3) is spelled out one obtains

I know that it is true that snow is white

as the fully explicit form of the assertion made through an assertoric utterance of the declarative (1).

In this assertion, truth is ascribed to the propositional content given by (4). The declarative sentence expresses a statement of the form "truth ascribed to propositional content". ${ }^{17}$ In the scholastic tradition, assertion is the external form of the interior act of judgement, and the assertion is the outward sign of the mental judgement made. The traditional form of judgement/assertion was

$\mathrm{S}$ is $\mathrm{P}$,

that is, a two-term judgement of subject/copula/predicate form. The above tale, from (1) to (7), provides a reason for abandoning the traditional form of judgement in favour of

A is true,

where $\mathrm{A}$ is a proposition, that is, equivalently, in favour of the form

that $\mathrm{S}$ is true,

where $\mathrm{S}$ is a declarative sentence.

It should be noted that my above route to the novel form is not the one that was actually taken by the logical pioneers, to wit Bolzano, who introduced the new form, and Frege, who reached the same conclusion: Ein Urteil ist mir nicht das bloße Fassen eines Gedanken, sondern die Anerkennung seiner Wahrheit. ${ }^{18}$

In the light of the above discussion the following picture emerges with respect to the act of knowledge: 
THE REALIST (BOLZANO-FREGE) THEORY

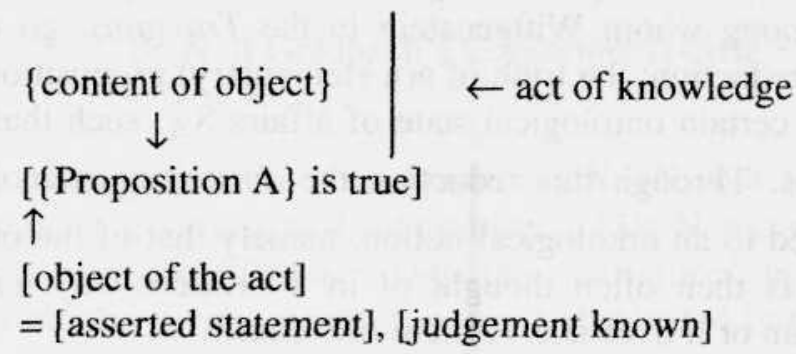

There are three interrelated levels in this schema:

The assertoric/judgemental act or deed; the statement used in the assertion/judgement ; the propositional content of the statement.

To each of the three notions there corresponds a suitable correctness notion, to wit:

the rightness (validity) of the act;

(iii') the correctness of the object of the act, that is, the asserted statement; the truth of the propositional content of the asserted statement .

Our task is now to determine the relative order of priority of these notions within the realist respectively antirealist positions.

The notion (i') is the most fundamental; it is required in order to avoid epistemological nihilism. Without the notion of rightness applied to our deeds there is no way to differentiate between appearance and reality, between Schein und Sein: the distinction between right and right-for-me is abolished and anything goes. There are various options as to how to secure the norm of rightness in question. One that was followed by Bolzano (and also by Frege) is to take the classical - bivalent truth of propositions as primitive: every proposition is true or false without further ado. One then readily explains the correctness of a statement in the following way: the statement that ascribes truth to a proposition is correct if the propositional content really is true, and the act of judgement is right if the (statement-)object is correct, that is, if the proposition that serves as content of the judgement made really is true. This radical and straightforward reduction of the rightness of acts, and of the correctness of judgements made, to the truth of propositions imposes a pleasing simplicity on the resulting realist epistemology. ${ }^{19}$

The Bolzano-Frege realist reduction makes all three notions of correctness subservient to propositional truth: the notion of truth that is applied to propositional contents then serves in all the offices of truth. The offices of truth, however, match the traditional theories of truth. Thus, under the realist reduction (whether tacit or explicit), with its conflation of the offices of truth, the traditional theories are turned 
into rival conceptions of truth for propositions: suddenly they are held to concern the same notion and impute different, and even contradictory, properties thereto.

For some realists the above epistemological reduction to propositional truth is not enough. Some, among whom Wittgenstein in the Tractatus, go even further and apply yet another reduction: the truth of a(n elementary) proposition $\mathrm{A}$ is reduced to the obtaining of a certain ontological state of affairs $S_{A}$, such that $A$ is true if and only if $\mathrm{S}_{\mathrm{A}}$ obtains. Through this reduction the desired epistemological notion of rightness is reduced to an ontological notion, namely that of the obtaining of states of affairs, which is then often thought of in a bivalent way: either the state in question does obtain or it does not. Tertium non datur.

The same pattern is obtained in modern versions of these views on knowledge and language, where a Tarskian model-theoretic semantics is applied to ordinary, or philosophical, discourse, and where the world is seen (often tacitly) as a (huge) relational structure in which every sequence of entities either does satisfy or does not satisfy a given "open sentence". ${ }^{20}$ In such a way, then, via a realist semantics, be it Tarskian or not, an ontological norm of rightness is secured that suffices to avoid epistemological nihilism.

\section{WITTGENSTEIN'S ONTOLOGICAL REDUCTION IN THE TRACTATUS}

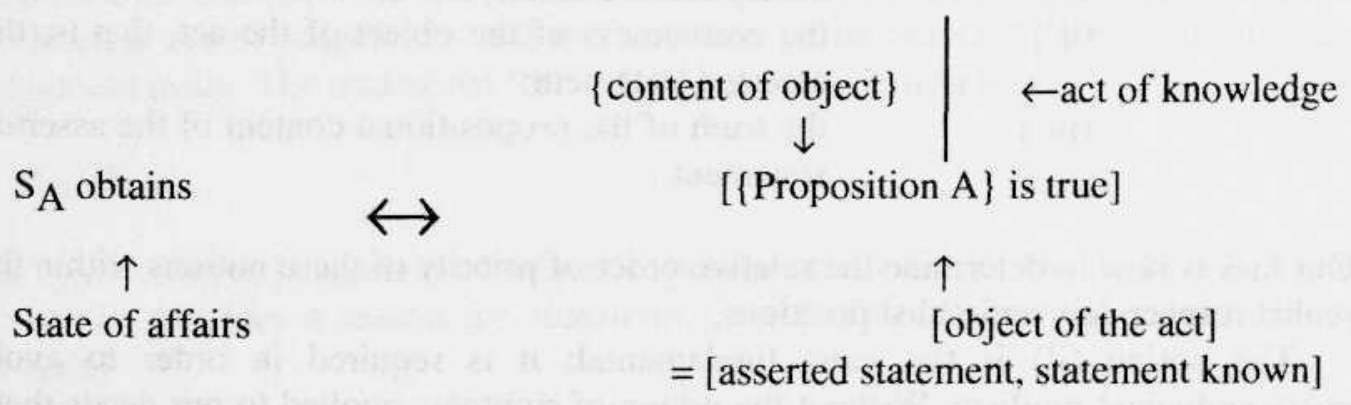

\section{PROPOSITIONS AND TRUTH}

The objects of the acts of assertion/judgement, that is the asserted statements/judgements made, ascribe truth to propositional contents, which can be rendered linguistically as that-clause nominalizations of declaratives. In order to complete the analysis, the notion of a proposition must be elucidated. Such an elucidation will contribute to both the negative and positive parts of the antirealist programme. The positive contribution, naturally enough, consists in a constructivist account of propositions, whereas the negative rests on the intuitionist criticism of non-constructive reasoning within mathematics.

This criticism was first voiced by Kronecker, who objected to the use of definitions by means of "undecidable", or perhaps better, as yet undecided cases. For certain number terms such definitions lead to computations that cannot be executed to a value in primitive, non-defined form. Consider the following example: 
$1 \in \mathbf{N}$, if Goldbach's Conjecture is true,

$\mathrm{f}(\mathrm{k})=\mathrm{def}$

$0 \in \mathbf{N}$, if Goldbach's Conjecture is false. ${ }^{21}$

This is meant to be a definition of a function $\mathrm{f}: \mathbf{N} \rightarrow \mathbf{N}$, but no values can be computed. For instance, according to the definition, $f(23) \in \mathbf{N}$, but we cannot indicate a natural number $k$ such that $f(23)=k .^{22}$ Thus this "definition" by undecided cases introduces defined number terms, which cannot be eliminated in favour of terms in primitive notation. Such "definitions" allow for definitional equalities in which the definiendum cannot effectively be replaced by the definiens, thereby contravening the canons on definition that have been upheld ever since Pascal. ${ }^{23}$

The classical logical theory of Bolzano and Frege is bivalent: every proposition is true or false; in fact, being true-or-false, in the classical theory, is a characterising mark of propositions. But something is true-or-false only if it is true or if it is false, or so it is said. The need for every declarative to have a truth-value poses severe problems, for instance in connections with the quantifiers. Frege's explanation of the universal quantifier runs (where I have only made explicit the dependence on the domain of quantification) as follows:

$\forall$-formation:

$$
(\forall \mathrm{x} \in \mathrm{D}) \mathrm{A}=\mathrm{def}
$$

The True, if $\mathrm{A}[\mathrm{a} / \mathrm{x}]=$ The True, for $\mathrm{a} \in \mathrm{D}$.

The False, otherwise,

where $\mathrm{A}$ is a propositional function over the domain $\mathrm{D}$, that is, $\mathrm{A}$ is a proposition, provided that $\mathrm{x} \in \mathrm{D}$.

When the domain D of quantification is infinite, or "unsurveyable", this separation of cases cannot be carried out effectively. It is exactly parallel to the above non-constructive way of attempting to define a function and it gives rise to similar difficulties: universal quantification, classically construed, introduces nonprimitive means of notation that cannot be eliminated. This, however, is nothing but a version of Brouwer's (1908) criticism of the unrestrained use of classical logic within mathematics. ${ }^{24}$ Note here that it is the universal quantifier formation rule that cannot be made evident on the classical conception of propositions: it simply is not clear that the universal quantifier takes a classical propositional function with respect to a domain into a classical proposition. ${ }^{25}$

Dummett has launched a controversial argument based on the presence of such "undecidable sentences" in the language (examples being quantification with respect to infinite domains, the remote past and future, sentience in others, and counterfactuals). Knowledge of a bivalent truth-condition for such an undecidable sentence cannot, in the end, Dummett holds, be "manifested", and so bivalent truth cannot serve as a key-concept in an adequate meaning theory for a sizeable language. ${ }^{26}$ 
To my mind the Kronecker-Brouwer rejection of classical bivalence more convincing, owing to its simplicity: if you want to avail yourself of classical logic across the whole board, irrespective of subject matter, you have to use defined expression that cannot be eliminated. Therefore, in a literal sense, the realist does not know what he is talking about. This, to me, is too high a price to pay. If one accepts this conclusion, the need for an alternative notion of proposition becomes obvious. Accordingly it is incumbent upon the constructivist to offer such an alternative.

\section{PROPOSITIONS: THE CONSTRUCTIVE ALTERNATIVE}

The 1920's constitute a period of transition in logical theory. ${ }^{27}$ The universalist "Logic as language" paradigm that had been adhered to by the pioneers Frege, Russell, and Wittgenstein was gradually replaced by the metamathematical "Logic as calculus" approach that was emerging in the works of, among others, Skolem, Bernays, and Hilbert. ${ }^{28}$ The novel metamathematical formal languages were, in the first instance, not meant for proving theorems in, but for proving (meta-)theorems about. The formal systems of the Grundgesetze and Principia Mathematica, on the other hand, were formulated as interpreted formal languages and the axioms and rules of inference had to be made evident under the given meaning explanations. Wittgenstein's Tractatus, in particular, can be seen as a grand attempt to provide a semantical foundation for Principia Mathematica. The works of Chwistek and Ramsey simplifying the theory of types also belong to this tradition. ${ }^{29}$ The early systems of Church, of Curry, of Quine, and above all, of the mature Lesniewski, all fall under the Logic-as-language conception. It should be stressed that Heyting's seminal (1930) also belongs here: the formalization is understood as an interpreted one, but in that work the basic notions are left largely unexplained. Heyting's creation, nevertheless, intensified an already confused debate concerning "Brouwerian logic": was it not really a many-valued logic, using a third truthvalue? ${ }^{30}$

Heyting (1930a) intervened in this debate, and, to all but few, put an end to the confusion. What he did was to give an explanation of the basic notions so that his formal systems became interpreted formal systems, more or less adequate for the expression of (part of) intuitionistic mathematics. In particular, Heyting articulated the relevant intuitionist notion of a proposition. From his intuitionist, or, as I prefer, constructivist, standpoint, a proposition is viewed as a problem (or expectation), which has to be solved by exhibiting a certain mathematical construction, namely its proof. His first example used the Euler-Mascheroni constant C:

The mathematical proposition

\section{Euler's constant is rational}

expresses the problem (or expectation) of finding a certain construction, namely a

$$
\text { pair of integers } p \text { and } q \text { such that } C=p / q \text {. }
$$


Heyting $(1931,1934)$ offered alternative formulations in terms of other basic concepts, and also Kolmogoroff (1932) gave an interesting alternative in terms of problems (Aufgaben) and their solutions. As Heyting (1958) came to realise, the various formulations were substantially equivalent. Finally, Howard (1969) introduced his formulae-as-types notion, which was refined by Martin-Löf (1984) into propositions-as-sets (of proof-objects). ${ }^{3 !}$

\section{ALTERNATIVE CONSTRUCTIVIST NOTIONS OF A PROPOSITION}

\begin{tabular}{l|l|l}
\hline Heyting (1934) & Proposition & proof \\
Kolmogoroff (1932) & Problem (task) & solution \\
Heyting (1931)(1930) & Intention (expectation) & fulfilment (realization) \\
Howard (1969) & Type & term \\
Martin-Löf (1984) & Set & element
\end{tabular}

This notion of proof of a proposition, it must be stressed, is novel with intuitionism: in the tradition a proof is always of a theorem, that is, what is proved is always at the level of a judgement. Prior to Heyting, the notion of a proof of a judgemental content had found no use. Previously, proofs were either proof-acts (through which one gets to know a theorem) or (what I, following Martin-Löf, shall call) traces of such acts. ${ }^{32}$ The novelty is reflected by the apt "proof-object" terminology that was introduced by Diller and Troelstra (1984). As is by now familiar, the meaning of a logical constant is explained in terms of how proof-objects may be formed for the propositions in which the constant in question serves as the main connective. The information may be presented in the form of "proof-tables" (which, from the point of view of meaning theory, play the same role as the truth-tables in classical semantics):
( $\perp$ Nothing is a proof of $\perp$.
(\&) When a is a proof-object for A and b is a proof-object for B, $<\mathrm{a}, \mathrm{b}>$ is a proof-object for $\mathrm{A} \& \mathrm{~B}$.
(v) When a is a proof-object for A, i(a) is a proof-object for AvB. When $b$ is a proof-object for $\mathrm{B}, \mathrm{j}(\mathrm{b})$ is a proof-object for AvB.
(つ) When $\mathrm{b}$ is a proof-object for $\mathrm{B}$, provided $\mathrm{x}$ is a proof-object for $\mathrm{A}$, $\lambda x . b$ is a proof-object for $A \supset B$.
$(\forall) \quad$ When $b$ is a proof object of $B$, provided that $x \in D$, $\lambda x . b$ is a proof-object for $(\forall x \in D) P$.
( $\exists$ When $a \in D$, and when $b$ is a proof-object of $B[a / x]$, $<\mathrm{a}, \mathrm{b}>$ is a proof-object for $(\exists x \in \mathrm{D}) \mathrm{P} .^{33}$

One should here note the strong similarity between Gentzen's introduction rules in natural deduction style and these meaning explanations. ${ }^{34}$ This suggests a necessary emendation in the reading of Heyting's clauses. What is given here is not a general formulation of how proof-objects for complex propositions may be formed out of proof-objects for their parts: these are explanations of how canonical (Brouwer), direct (Gentzen), primitive proofs may be formed out of parts, in analogy with how the primitive, or canonical, number terms 


$$
0, \mathrm{~s}(0), \mathrm{s}(\mathrm{s}(0)), \mathrm{s}(\mathrm{s}(\mathrm{s}(0))), \ldots,
$$

are given by the rules NI

$$
0 \in N \quad \text { and } \quad \frac{a \in N}{s(a) \in N .}
$$

However, as we all know, it is also possible to form non-primitive, defined, number terms, for instance,

$$
14 !+([93 / 6] \cdot[3+8]) \text {. }
$$

The only constraint that is put on the use of such terms is that they admit of evaluation to a numerical value, that is, a number term in canonical form. Similarly, the only condition put on the means used for forming (non-canonical) proof-objects is that they admit of evaluation (or normalization, in the terminology of Prawitz) to canonical form. ${ }^{35}$ In particular, in view of the reduction steps used in Prawitz's proof-theoretic normalization theorems, the standard elimination rules for the constructive logical constants are permitted in the formation of (non-canonical) proof-objects.

Consider, for instance, Prawitz's so called \&-reduction according to which the derivation

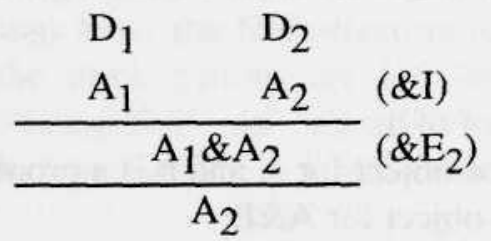

reduces to the derivation

$$
\begin{aligned}
& D_{2} \\
& A_{2} .
\end{aligned}
$$

In linearized form, where the introduction- and elimination-rules are means for forming proof-objects, this becomes:

when $\mathrm{D}_{1}$ is a derivation of $\mathrm{A}_{1}$ and $\mathrm{D}_{2}$ is a derivation of $\mathrm{A}_{2}, \boldsymbol{\&} \mathbf{E}_{2}\left(\& \mathbf{I}\left(\mathrm{D}_{1}, \mathrm{D}_{2}\right)\right)=$ $\mathrm{D}_{2}$ is a proof of $\mathrm{A}_{2}$.

The analogy with:

when $d_{1}$ is a proof of $A_{1}$ and $d_{2}$ is a proof of $A_{2}$, 
$\mathbf{p}_{2}\left(<d_{1}, d_{2}>\right)=d_{2}$ is a proof of $A_{2}$,

where $\mathbf{p}_{2}$ is the right-hand projection-operation associated with pair-formation (and which yields the second component upon application to a pair), should be obvious.

In summary, then, under the proof explanation of the constructive notion of proposition, to each proposition A there is associated a set (which might turn out to be empty in case the proposition is false) of proof-objects for A. Truth is then readily explained by means of a so called truth-maker analysis (with the proofobjects serving as truth-makers). ${ }^{36}$

The proposition $\mathrm{A}$ is true $=$ there exists a proof of $\mathrm{A}$.

This truth-condition for the proposition $\mathrm{A}$ is determined by (i) the proof-condition for $\mathrm{A}$ and (ii) the relevant notion of existence. The kind of existence that is here at issue is not that of the existential quantifier. The $\exists$-quantifier applies to propositional functions only, whereas the relation

\section{$\Pi(\mathrm{a}, \mathrm{A})=\operatorname{def} \mathrm{a}$ is a proof of the proposition $\mathrm{A}$}

is not propositional in nature: we do not explain $\Pi(\mathrm{a}, \mathrm{A})$ by telling how a proofobject for this would be put together out of parts, owing to an infinite regress of ever-descending proof-explanations. ${ }^{37}$ The relevant notion of constructive existence was made explicit by Hermann Weyl (1921):

I am entitled to claim that there exists an $\alpha$ only after having instantiated $\alpha{ }^{38}$

Here, then, we have a novel form of judgement: when $\alpha$ is a (general) concept

$\alpha$ exists

is a judgement, the assertion condition of which is given by the rule

$\frac{a \text { is an } \alpha}{\alpha \text { exists. }}$

The constructivists, though, are not the first to use existence as a form of judgement. In particular, they were anticipated by Brentano, who used only the two forms of judgement

$\alpha$ IS ( or exists)

and

$\alpha$ IS NOT (or does not exist). ${ }^{39}$ 
The four traditional forms of categorical judgement were then reduced to these two forms. For instance,

All $\alpha$ are $\beta$

was reduced to

An $\alpha$ which is not $\beta$ does not exist. ${ }^{40}$

When applied in the truth-condition of the proposition A, the constructive notion of existence yields a formulation of the assertion-condition for the statement that $\mathrm{A}$ is true:

One is entitled to assert that $\mathrm{A}$ is true,

only after having constructed a proof-object a for $\mathrm{A}$.

This analysis (which is due to Per Martin-Löf (1994)) of the constructive form of judgement is, it should be noted, in a certain sense an epitome of the work of the previous century:

\section{FORMS OF JUDGEMENT:}

\begin{tabular}{|c|c|c|}
\hline $\begin{array}{l}\text { Traditional form: } \\
\text { Bolzano form: } \\
\text { Brentano form: } \\
\text { Truth-maker form: }\end{array}$ & \multicolumn{2}{|c|}{$\begin{array}{l}\mathrm{S} \text { is } \mathrm{P} \\
\text { proposition } \mathrm{A} \text { is true. } \\
\alpha \text { exists } \\
\text { there exists a truth-maker for } \mathrm{A}\end{array}$} \\
\hline \multicolumn{2}{|r|}{ Realist truth-maker analysis: } & Constructive truth-maker analysis: \\
\hline \multicolumn{2}{|r|}{ Bestehen of a Sachverhalt } & $\begin{array}{l}\text { there exists a proof of } \mathrm{A} \\
\text { which is reducible to } \\
\text { a is a proof of } \mathrm{A} \text {. }\end{array}$ \\
\hline
\end{tabular}

Thus the constructivist truth-maker analysis of

proposition $\mathrm{A}$ is true

is obtained by applying the Brentano form of judgement to the concept:

$$
\text { proof(-object) of A. }
$$

That form of judgement, that is,

$$
\text { proof(A) exists }
$$

is further reduced to an instance of the traditional form of judgement by means of an application of the constructivist analysis of existence: 
$\mathrm{a}$ is (an element of) proof(A).

The constructive notion of propositional truth must not be understood in a modalized way: 'existence' does not mean 'possibility to find' in the formulation of simple truth. This can be seen by considering the different types of assumptions that result from the two notions in question. An assumption that $\mathrm{A}$ is true, that is, that a proofobject for A exists, is what we use in natural deduction when we aim to demonstrate the truth of a certain implication $\mathrm{A} \supset \mathrm{B}$. The use of such an assumption in no way presupposes that a proof-object for can actually be found; on the contrary, we all know of true implications with false antecedents. An assumption that $\mathrm{A}$ is true is compatible with the set proof(A) actually being empty. ${ }^{41}$

An assumption, on the other hand, that a proof-object can be found for A entails that the set A cannot turn out to be empty. It is instructive to carry out the discussion in terms of proof-objects, rather than in terms of truth. An assumption that A is true means considering an assumption of the form

$\mathrm{x} \in \mathrm{A}$.

Such an assumption can be used to infer, for instance, that $A \supset A$ is true, irrespective of the actual truth-value of $\mathrm{A}$, by constructing the proof-object

$\lambda x . x \in A \supset A$.

For another example, consider a derivation involving the above \&-elimination rule: assume that $\mathrm{z}$ is a proof of $\mathrm{A} \& \mathrm{~B}$. Under this assumption, $\mathbf{p}_{2}(\mathrm{z})$ is a proof of $\mathrm{B}$. Therefore, discharging the assumption that $\mathrm{z}$ is a proof of $\mathrm{A} \& \mathrm{~B}$,

$$
\lambda z \cdot \mathbf{p}_{2}(z) \in A \& B \supset B
$$

which judgement holds irrespective of whether the propositions A and B are actually true.

The second assumption, that a proof-object can be found for A, assumes that $\mathrm{A}$ really is true, that is, that a proof-object $a \in A$ is obtainable. Under this assumption, it is incoherent that proof(A) turns out to be empty. An assumption that a proof-object of A can be found is, according to the explanations offered previously, the same as an assumption that the statement $\mathrm{A}$ is true is demonstrable (knowable), because in order to know that the proposition $\mathrm{A}$ is true, that is, in order to know that proof(A) exists, I must instantiate proof(A) by means of a proof-object. So, if it is demonstrable that $\mathrm{A}$ is true, a proof-object can be found. In order to grasp the difference we may consider an example. For every natural number k,

$$
P(k)=\text { that } k \text { is the number of window-panes in the City Hall of Leyden }
$$

is a proposition. Hence, for every $k \in N$,

$\mathrm{P}(\mathrm{k})$ is true 
is a judgement (in the sense that its assertion-condition is determined). Truth can be demonstrated, however, only for one $\mathrm{P}(\mathrm{m})$ and the proof-object required for the truth of $\mathrm{P}(\mathrm{m})$ can be found as the result of a (tedious) counting-process.

An assumption, now, that $P(k)$ is true may be used in the following way: "Assume that $\mathrm{P}(\mathrm{k})$ is true. The window-cleaning cost in Dutch guilders is 4 times the number of panes. Therefore, under our assumption, we should reserve $4 \times \mathrm{k}$ :- D. fl. in our budget. Therefore, the proposition

$(\forall \mathrm{k} \in \mathrm{N})$ (that $\mathrm{P}(\mathrm{k}) \supset$ that $4 \times \mathrm{k}$ :- D. fl. must be reserved in the budget)

is true. The truth of this proposition is compatible with any number of window panes. $^{42}$

The other type of assumption leads to a different situation. "Assume that $\mathrm{P}(10.100)$ really is true. Then 40.400 :- $\mathrm{D}$. $\mathrm{fl}$. is the sum that we must reserve for the cleaning costs." Any other sum will, under the given circumstances, be off the mark and will make the budget incorrect.

Demonstrability ("provability") of statements, that is, truth for statements, is a modal notion, but truth for propositions is not. The matching two types of assumptions might be characterized as epistemic assumptions that statements are knowable versus alethic assumptions that propositions are true.

\section{CORRECTNESS ("TRUTH") OF JUDGEMENTS.}

For Brentano the judgement (statement), rather than the proposition (which notion he rejects), is the primary truth-bearer. His account of truth is a modal fusion of a correspondence theory and an evidence-theory of truth:

a judgement is correct (richtig) if it agrees with (or corresponds to) the judgement that would be made by someone who judges with evidence. ${ }^{43}$

Above I tied the correspondence notion to the truth of propositions, and I therefore prefer, following Martin-Löf, to account for the modal and evidence-theoretical components in a slightly different fashion:

a statement is correct (true) if it can be made with evidence.

The true statements are the evidenceable, knowable, warrantable, justifiable, ... ones. According to the discussion towards the end of the previous section, the statement that $\mathrm{A}$ is true is correct, that is, demonstrable, when a proof-object for the proposition A can be found.

Brentano, however, did not just construe judgemental truth according to an evidence theory. He also wished to locate the norm of rightness in the notion of evidence: 
Bei Evidenz ist Irrtum ausgeschlossen. Bei Evidenz ist auch Zweifel ausgeschlossen, aber weder Freiheit von Irrtum noch Freiheit von Zweifel macht das Urteil zum evidenten Urteil, sondern eine Eigentümlichkeit, die es als richtig charakterisiert. ${ }^{44}$

Here he goes to far in my opinion: the criterion of evidence is the Cartesian 'clear and distinct', but Brentano wishes this to be a criterion not only for evidence but also for freedom from error. According to him, when something is judged clearly and distinctly, error is ruled out. However, evidence is what makes us know, and thus, when evidence is taken to guarantee freedom from error, knowledge is infallible and error is ruled out. But error can never be ruled out. Hence evidence must not be conceptually equated with freedom from error. When error is diagnosed, the reaction will be: I thought it was evident, but in reality it was not.

The classical (Bolzano) view, as we saw above in section 3, gains great simplicity by reducing the correctness of the judgement

$\mathrm{A}$ is true

to the truth of the propositional content $\mathrm{A}$. When the proposition $\mathrm{A}$ is true, Bolzano says, the judgement in question is correct (richtig), that is, it is a piece of knowledge (a cognition, an Erkenntnis). ${ }^{45}$ On this reading, judgements which are, in the apt terminology of Brentano, blind, that is, unwarranted, are still held to be knowledge, simply in virtue of having a (classically) true proposition as content. An example would be a judgement made, completely without warrant, by hazarding a mere guess as to the number of window-panes in the Leyden City Hall, say, 8548, and hitting bull's eye by fluke. To my mind, blind knowledge is to high a price to pay for the Bolzano-reduction of judgemental correctness to propositional truth, since,

opinions divorced from knowledge, are ugly things[.] The best of them are blind. Or do you think that those who hold some correct opinion without evidence differ appreciably from blind men who go the right way? ${ }^{46}$

Accordingly, I prefer the opposite route, explaining propositional truth as a particular form of judgement, and the judgemental correctness as evidenceability.

\section{VALIDITY OF INFERENCES.}

Corresponding blindness phenomena may occur also at the level of inference. Here, the classical notion of validity is applicable to an inference(-mode) of the form I':

$\frac{A_{1} \text { is true } \quad A_{2} \text { is true } \quad \ldots \quad A_{k} \text { is true }}{C \text { is true }}$

Such an inference I is valid, or so Bolzano says, when a relation of logical consequence - eine Ableitbarkeit - obtains between the propositions that serve as premisses, respectively conclusion, of the inference in question, that is, when the consequence

$$
A_{1}, A_{2}, \ldots, A_{k} \Rightarrow C
$$


obtains logically. In this Bolzano was followed by virtually the entire modern tradition in classical logic. Similar accounts of validity can be found in Wittgenstein's Tractatus, as well as in Tarski's (1936) account of logical consequence, whose current model-theoretic (Tarski-Vaught (1957)) version can be found in any decent text-book. ${ }^{47}$ However, also here the price paid for the ensuing simplicity is high. The key notion in the explanation of the (logical) holding of a consequence is that of truth under a variation (or truth in a model). A consequence holds logically if every variation that serves to make all the antecedent propositions true also makes the consequent proposition true. In fact, a consequence holds if the corresponding implicational proposition is true, and it holds logically if the implication is a logical truth. Accordingly, just as the reduction of judgemental correctness to propositional truth allowed for judgements that were blindly correct, so does the corresponding reduction of inferential validity to the (logical) holding of consequences allow for blindly correct inference. We get a similar epistemological slack between what is theoretically permissible and what is epistemically warranted: under the Bolzano reduction, the inference may be valid, even though no epistemological warrant has been offered in order to make the conclusion evident. Thus, under the classical Bolzano reduction of validity, we could find ourselves in the position that we knew the premisses of an inference, and, furthermore, that, unknowingly to us, logical consequence does obtain between the relevant propositional contents of premisses and conclusion. In such a position one would be allowed to carry out the inference - because under the Bolzano reduction the inference is valid - but still we would not know the conclusion. This situation would be an example of an unknown conclusion that is validly drawn from known premisses. We would have a (mediate) act of knowledge, in which all the premisses were known and the inference valid, according to the appropriate, Bolzano-reduced notion of validity, but which would not make its object evident.

It now remains to offer a constructivist account of validity that does not suffer from the shortcomings of the Bolzano reduction. The blindness-phenomena that impugn the Bolzano-reduced notions of validity and (judgemental) correctness have their origin in the circumstance that propositional truth is not primarily epistemic. Evidence is conferred upon what is known, namely a certain statement (judgement), by the act of knowing. In the case of an immediate act, the statement must be evidenceable from itself: the knowledge is intuitive rather than discursive. In a mediate act, discursive knowledge is inferred, that is, is drawn as a conclusion, from certain evident judgements. Thus, what is called for, in a constructivist elucidation of inferential validity, is not preservation of propositional truth, but transmission of judgemental evidence from statement(s) to statement. This leads straightforwardly to a resurrection of the old idea that the validity of an inference resides in the analytic containment of the conclusion in the premisses. Thus we say that the inference I

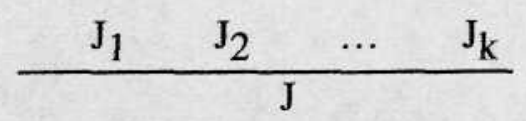


is valid when a chain of evidence-preserving steps $\Sigma_{1}, \Sigma_{2}, \ldots, \Sigma_{\mathrm{m}}$ can be given, which links premisses and conclusion, and where each $\Sigma_{\mathrm{i}}$ is either an axiom, that is, a self-evident (immediate) judgement, or an immediately valid inference, that is, an inference the evidence-preservingness of which rests in the nature (essence) of the concepts that are used the inference in question, and which, accordingly, neither is capable, nor is in need, of further justification in terms of other inferences. ${ }^{48}$ It is interesting to note that this notion of validity, in terms of chains of immediate evidences, crops up now and then, even in modern mathematical logic. Thus Gödel holds that 'the chain of definitions of the concepts occurring in the theorem together with certain axioms about the primitive terms forms by itself a proof, i. e., an unbroken chain of immediate evidences' ${ }^{49}$ Similarly, according to H. B. Curry's description of the intuitionist position,

'a proof is valid when it is a construction the individual steps of which are immediately evident; no matter what rules are given, a valid proof can be found which does not conform to them'. ${ }^{0}$

The notion of validity that was discussed above pertains to (modes of) inference. However, in the quote from Curry, another notion occurs. There, what is at issue is the notion of a valid proof. We have encountered three notions of proof that have to be carefully kept apart, namely,

proof(-act)s of certain theorems;

proof(-trace)s of such acts, that is, demonstrations in mathematical texts; proof(-object)s of propositions.

The second of these is the natural carrier of the above notion of validity. Proof(trace)s are blueprints for, in general, discursive, mediate proof-acts. When a trace is valid, that is, when all the axioms that occur in the trace are (self-)evident, and all the inference(-modes) that occur are valid, then an act carried out according to the trace confers evidence upon its conclusion.

Rightness -rectitudo - is the relevant notion for the level of (proof- and other) acts as was already noted. ${ }^{51}$ It is sui generis and is needed to account for the possibility of error. Without the notion of rightness, error would be an empty notion.

Of course, we can also speak of right proof-objects. This would yet again be an application of the notion of rightness, this time in the form of truth of things: concerning a judgement of the form

$$
c \in \operatorname{proof}(\mathrm{A})
$$

the question may arise whether it really is evident and whether $c$ really does belong to proof(A). Confronted with such a situation, we are perhaps able, after discussion and evaluation, checking each construction-step that has been used in synthesizing the putative proof $c$, to satisfy ourselves that we were not mistaken:

$\mathrm{c}$ is a right proof(-object) of $\mathrm{A}$. 


\section{ANALYTICITY AND THE GÖDEL INCOMPLETENESS THEOREMS}

Above, axioms were called analytic and the validity of inference was explained in terms of 'analytic containment' between conclusions and premisses. ${ }^{52}$ From Aristotle's Posterior Analytics, with its treatment of per se predications, the notion of analyticity has had a central role in epistemology. Medieval epistemology, for instance, in Aquinas and Duns Scotus, treats of demonstrative knowledge in terms of "self-evident" judgements, that is, statements that are knowable in themselves. In fact, the explanation offered by St. Thomas Aquinas for the notion of a propositio per se nota is the same as that of Kant for the notion of an analytic judgement: ${ }^{53}$ An $\mathrm{S}$-is-P judgement is knowable per se when the predicate $\mathrm{P}$ is contained in the essence (or concept) of the subject $\mathrm{S}$, so that knowledge of the definitions of $\mathrm{S}$ and $\mathrm{P}$, that is, knowledge of their essences, suffices for knowledge of the judgement itself. ${ }^{54}$ On the road to Kant, one encounters the trifling propositions of Locke, as well as the deviant variation that was adhered to by Leibniz, according to whom all truth is analytic. However, even Leibniz does not fall into the trap of making all of (analytic) truth knowable per se. Any S-is-P truth has an a priori proof that is obtained by resolving the terms $\mathrm{S}$ and $\mathrm{P}$ to their essential constituents. Owing to the analyticity of the truth in question the resolution has to stop in identities and the result is a proof when read in the opposite direction. However, only in the case of a truth of reason is the priori proof a finite one. In the case of a Leibnizian truth of fact, on the other hand, the process of resolution will, in general, not terminate after a finite number of steps, whence only the infinite mind of God is capable of taking in the a priori proof. Hence, according to Leibniz, other means, and not merely those present in the terms themselves, are required for us finite minds in order to know such truths of fact.

Martin-Löf (1994) notes that his type-theoretical judgements of the two forms

a: $\alpha$, that is, a is of object of type $\alpha$,

and, where a and $\mathrm{b}$ are both object of type $\alpha$,

$\mathrm{a}=\mathrm{b}: \alpha$, that is, $\mathrm{a}$ and $\mathrm{b}$ are equal objects of type $\alpha$,

have the required analytic character. It is enough to have ' $a$ ' and ' $\alpha$ ' in order to be able to decide whether a: $\alpha$ (and similarly for judgements of equality. For both kinds of judgement, the means of decision utilizes evaluation to, and inspection of, relevant canonical forms). On the other hand, judgements of the form

A is true,

that is, of the form

proof(A) exists, 
are synthetic, since they cannot be known merely from their own formulation, but demand a construction, or synthetization, of a proof(-object). Thus, the truth of a mathematical proposition, indeed of 'ein jeder Existentialsatz', is synthetic. On the other hand, that the proof(-object) is a proof(-object) of what it proves is something which can, in order to speak with Wittgenstein's Tractatus, be read off analytically am Symbol allein. ${ }^{55}$

A beautiful feature of Martin-Löf's view is that every synthetic truth is grounded in an analytic judgement: when a proposition $\mathrm{C}$ can be known to be true, that is, when we can know the judgement

$\mathrm{C}$ is true,

we can also know of a certain construction c, such that the judgement

$\mathrm{c}$ is a proof of the proposition $\mathrm{C}$

is analytically correct, that is, can be known mechanically from the symbol alone.

In general, since it is a question of meaning, it is analytic (ex vi terminorum) that a certain proposition is made true by a certain kind of truth-maker. Whether such a truth-maker exists, on the other hand, is something that demands amplification (Erweiterung) of our knowledge, rather than mere elucidation (Erläuterung). Something of the this sort, of course, holds also for the classical truth-maker analysis in Wittgenstein's Tractatus. That a proposition (sinnvolle Satz) A is true cannot be known a priori, but demands comparison with the world; it must be checked that the presented state of affairs (Sachverhalt) $\mathrm{S}_{\mathrm{A}}$ does indeed obtain. The relation between the proposition $A$ and the state of affairs $S_{A}$ that it presents, on the other hand, is internal. Thus, what a truth-maker is for A is internally determined from A, whereas the question of the existence of such a truth-maker is a material one, that is, one that cannot be answered merely from the symbol alone.

In Wittgenstein's Tractatus, as well as for Bolzano, the important notion is not that of an analytic judgement. ${ }^{56}$ Instead the notion of a logically true proposition, which Wittgenstein calls tautology, and Bolzano logically analytic proposition (or 'analytic in the narrow sense'), that is, a proposition which is true, come what may, independently of what is the case, holds pride of place. ${ }^{57}$ In the Tractatus Wittgenstein transfers the demand of per se recognizability from the notion of an analytic judgement to the notion of a logical truth: it must be possible, by mechanical calculation on the symbol alone, to determine whether the proposition is a tautology. ${ }^{58}$ As noted by Wittgenstein, the decision method offered in the Tractatus, however, is applicable only in the case of quantifer-free propositions. ${ }^{59}$ The undecidability of predicate logic, finally, that was established by Alonzo Church (1936), made it an illusionary hope that such a method could be found for the whole of language: in general, the notion of logical truth for propositions containing multiple generality, that is, occurrences of the quantifier combinations $\forall \exists$ and $\exists \forall$, is recursively undecidable. The logic of judgements of the two categorical forms 
a is an object of type $\alpha$, respectively, a and b are equal objects of type $\alpha$

is decidable, whereas the logic of judgements of the form

$\mathrm{A}$ is true, that is, proof (A) exists,

is undecidable, in virtue of Church's theorem.

How do matters stand with respect to the other great limitative theorem, namely Gödel's (1931) Incompleteness Theorem? Let us attempt to transpose the Gödel theory to the present framework. A system S of rules for generating proof(-objects) is consistent, if the judgement

$$
\mathrm{t} \in \perp
$$

can be derived for no term $\mathrm{t}$ from the rules of $\mathrm{S}$. Consider now a consistent system $\mathrm{S}$ that comprises a modicum of arithmetic, say, in the form of construction-rules for proof-objects corresponding to the natural deduction rules

$$
\& \mathrm{I}, \& \mathrm{E}, \square \vee \mathrm{I}, \vee \mathrm{E}, \supset \mathrm{I}, \supset \mathrm{E}, \perp \mathrm{E}, \forall \mathrm{I}, \forall \mathrm{E}, \exists \mathrm{I}, \exists \mathrm{E}, \square \mathrm{IdI}, \mathrm{IdE}, \mathrm{NI}, \mathrm{NE},
$$

The rule IdI for identity (among the elements of the set A) takes the form

$$
\frac{a \in A}{r(a) \in \operatorname{Id}(A, a, a)}
$$

and IdE is the corresponding elimination rule. NI, on the other hand, is the introduction rule that generates the canonical forms of numbers, and NE allows for proofs by means of mathematical induction over the set $\mathrm{N}$, by means of permitting the definition of functions by recursion. The work of Gödel, when transposed to the present framework, shows that, by inspection of the rules of $S$, we can explicitly indicate a true proposition $\mathrm{G}_{\mathrm{S}}$ of $\mathrm{L}_{\mathrm{S}}$ such that for no term $\mathrm{t}$ of the language $\mathrm{L}_{\mathrm{S}}$ of the system $\mathrm{S}$ can the judgement

$$
t \in \operatorname{proof}\left(G_{S}\right)
$$

be derived from the rules of $\mathrm{S}$, even though the proposition $\mathrm{G}_{\mathrm{S}}$ is formulated using concepts in $\mathrm{L}_{\mathrm{S}}$ only. However, the truth of $\mathrm{G}_{\mathrm{S}}$ can be demonstrated in a suitable conservative extension $S^{\prime}$ of the system $S$, where a term ' $t^{\prime}$ can be found, together with a demonstration of the judgement

$$
\mathrm{t}^{\prime} \in \operatorname{proof}\left(\mathrm{G}_{\mathrm{S}}\right)
$$

from the rules of $\mathrm{S}^{\prime}$. The true proposition $\mathrm{G}_{\mathrm{S}}$ is itself arithmetical, that is, formulated in terms of purely arithmetical concepts, but its proof can be obtained only using non-arithmetical concepts: the term t' cannot be formed in the language $\mathrm{L}_{\mathrm{S}}$ of the 
system $\mathrm{S}$, but only in the extended language $\mathrm{L}_{\mathrm{S}}$ ' of the system $\mathrm{S}$ '. The Gödel Incompleteness strikes, not at the complete logic of analytic judgements, but against the incomplete logic of propositional truths, that is, judgements of the form

proposition $\mathrm{A}$ is true.

Let $\mathrm{S}_{\mathrm{PROP}}$ be the system of propositional truths that is obtained by stripping off the proof-objects from the theorems of S, that is, by replacing the $\mathrm{S}$ theorem

$\mathrm{c} \in \operatorname{proof}(\mathrm{A})$

by the truncated $S_{\text {PROP }}$ theorem

A is true.

The Gödel theorem then says that, for certain systems S and S', the matching system of propositional truths S'PROP will not extend $S_{\text {PROP }}$ conservatively, even though the system S' is a conservative extension of $S^{60}$ Gödel shows that the logic of propositional truth is incomplete. For analytic judgements, on the other hand, where the proof(-object)s of propositions have not have not been suppressed in the theorems, completeness does hold. If an analytic judgement $\mathrm{J}$ of the form

$\mathrm{a} \in \alpha$

is formulated in a language $\mathrm{L}_{\mathrm{S}}$, one will find a demonstration of $\mathrm{J}$ by means of applying the introduction and elimination rules of proof-construction from the construction-principles in $\mathrm{S}$ backwards.

Here, I think, lies a definite advantage of the constructivist position. In the Tractatus Wittgenstein rejects in scornful terms any use of 'das Einleuchten' - (self)evidence - in logic. ${ }^{61} \mathrm{He}$ has, however, not taken proper notice of the fact that his demand that the propositions of logic be mechanically decidable am Symbol allein is nothing but a variant of the traditional demand that the primitive propositions of logic be knowable per se, that is, that they can be made evident from themselves and do not demand an external comparison with the world. Just as Kant's analytic judgements they offer no extension but only elucidation of our knowledge. Wittgenstein simulataneously both rejects and imposes this demand for analytical self-evidence, whence his position becomes impossible. The constructivist epistemological alternative that I have been concerned to outline in the present Chapter, on the other hand, suffers no ill fate at the hand of the Incompleteness and Undecidability theorems, and this, to my mind, constitutes a powerful argument in its favour.

Göran Sundholm

Leyden University 


\section{NOTES}

${ }^{1}$ See for instance the essays collected in his (1978) and (1993), as well as the synoptic (1991).

${ }^{2}$ Grundgesetze, I, § 32, respectively Tractatus 4.024. David Wiggins (1980), (1992), (1997), in particular, has persistently explored the possibilities of this truth-conditional paradigm.

${ }^{3}$ Evidence is the quality that pertains to what is evident, and it is commonly expressed in terms of the Cartesian 'clear and distinct'. This evidence of what is evident must be distinguished from the evidence for an opinion. (The latter notion is not at issue in the present chapter.) The locus classicus for the evidence theory of truth is Brentano (1930, IV). 'Das Problem der Evidenz', that is, Stegmüller (1954, Ch. I.4), is an excellent introduction to the role of evidence in epistemology. Patzig (1971) is also illuminating, whereas Schlick (1910) offers a critical exposition.

${ }^{4}$ I am here indebted to Per Martin-Löf (1998).

${ }^{5}$ See Olson (1967).

${ }^{6}$ St. Augustine's Soliloquies and St. Anselm's De veritate are the prime sources concerning the notion of rectitudo.

${ }^{7}$ Fichte (1797).

${ }^{8}$ The act/object dichotomy raises the issue of the corresponding correctness notions: as a rule I shall reserve right for acts and correct for objects, for example, "the object of a right act of judgement is correct".

${ }^{9}$ See, respectively, Brentano (1930, Section IV), Patzig (1967), as well as Putnam (1981) and many later writings.

${ }^{10}$ Duns Scotus (1987, p. 106 and p. 126, respectively). The fascinating scholastic teaching on these matters is admirably treated by Vier (1951).

${ }^{11}$ Quine(1951, p. 21 and p. 22).

${ }^{12}$ In the German tradition, for instance, in Frege, one finds the distinction between Schluss (act) and Schlussweise (mode of inference).

${ }^{13}$ See Martin-Löf (1985) and other works listed in its Postscript.

${ }^{14}$ The notion of an assertoric utterance is here the prior one. The assertoric utterances of declaratives are delineated by means of the criterion involving the legitimacy of the counterquestion (2): inquiry as to how the utterer knows is legitimate after an assertoric utterance and in other cases not.

${ }^{15}$ The third person propositional claim Göran Sundholm knows that snow is white is different from the sense of (3) that is here at issue. In order to understand this, the Moorean paradoxes which lurk around the corner might be reflected upon: since I might forget, or be otherwise confused about my identity, an assertion by me of

Snow is white, but Göran Sundholm does not believe it

is not paradoxical, whereas an assertion by me (or anyone else) effected by means of an assertoric utterance of

Snow is white, but I do not believe it

is. Under the analysis in the text, in both cases, we get the illocutionary knowledge claim

I know that snow is white,

which, together with,

1 do not believe it,

does yield a Moorean paradox. My assertion of

Göran Sundholm does not believe it, 
on the other hand, does not yield a paradox, unless the additional claim that I know that I am Göran Sundholm is also given.

${ }^{16}$ In order to avoid offensive iterations of that it is often convenient to use the form (6).

${ }^{17}$ Warning. Ever since Cook Wilson the term statement has been overburdened in Oxford philosophy. My 'statements' do not coincide with Dummett's: his statements come close to my propositions, but are also intended to take indexicality into account, a topic that I prefer to leave out of consideration. My use is also different from that of Frege. For Frege, the declarative expresses a proposition (Gedanke) and this proposition may or may not be asserted. Given that it is the nominalizations 'that S' of declaratives $S$ that stand for propositions, I hold that Frege is wrong in this and that propositions are not behauptungsfähig. On the contrary, it is the statement expressed by the declarative S, namely the statement that it is true that $\mathrm{S}$, that is capable of being asserted.

${ }^{18}$ Bolzano (1837, $\$ 34$ ), and Frege (1892, p.34, fn. 7).

${ }^{19}$ Independently of the chosen epistemological position, a mistake is an act of knowledge which is not right. Under the realist reductions the rightness of acts of knowledge is reduced to the correctness of their products and that in turn to the truth of the propositional contents. But from a realist point of view propositional truth is bivalent: the proposition A either is, or is not, true, tertium non datur. From the constructivist point of view (which opts for the opposite alternative in the Fichtean dichotomy and upholds the primacy of acts), on the other hand, the rightness of acts is primitive, sui generis.

${ }^{20}$ This theme is worked out in some detail in my (1994). Niniluoto (1997) argues against some of the conclusions I drew there.

${ }^{21}$ The example is taken from Rogers (1967, p. 9-10). It is manufactured for a purpose, but it is not farfetched. Compare, for instance, the analogous example of Dirichlet, concerning the characteristic function of the rational numbers within the reals, which is highly significant from a mathematical point of view.

${ }^{22}$ The use of the set-theoretic $\epsilon$ in place of the type theoretic colon : is natural when the type in question is also a set.

${ }^{23}$ These canons are well set out in Dubislav $(1931, \S 14)$.

${ }^{24}$ I have learned this way of presenting Brouwer's argument from Aarne Ranta (1994, Chapter 2.14, pp. 37-38). With the benefit of hindsight I can find it already in Martin-Löf (1985, p. 33).

${ }^{25}$ There is, of course, nothing special about the universal quantifier: the analogous way of construing the existential quantifier produces the same quandaries.

${ }^{26} \mathrm{See}$, in particular, 'The philosophical basis of intuitionistic logic' (1975) and 'What is a theory of meaning? II' (1976), reprinted respectively in (1978) and (1993). There is, however, no consensus even as to how, precisely Dummett's argument goes; a massive scholarly debate has arisen, to which my (1987) is a relatively early contribution.

${ }^{27}$ The transition is beautifully described by Warren Goldfarb (1979).

${ }^{28}$ The distinction between the two logical paradigms was introduced by Jean van Heijenoort (1967), (1976). Jaakko Hintikka (1996) has tirelessly explored its possibilities.

${ }_{29}$ Gödel's (1944) essay for the Schilpp volume on Russell deals with these issues in considerable depth.

${ }^{30}$ Thiel (1988) and Franchella (1994) survey the debate in question.

${ }^{31}$ Detailed arguments concerning the equivalence between the formulations in terms of propositions that express intentions towards constructions and in terms of problems that require solutions can be found in my (1983, pp. 158-9), and (1997, p. 196).

32 The notion of trace is dealt with in considerable detail in my (1993), (1997), (1998) and (forthcoming). 
33 These formulations are not taken directly from Heyting, but are inspired by formulations used by Martin-Löf (1984). A proof of a mathematical theorem (that we can be found in a certain mathematical text) is such a proof-trace. It can be used as a "blue-print" for proof-acts by other mathematicians in order to get to know the theorem in question. Other examples are the scores of chess-games (which can be used by other players to imitate opening novelties etc.) and, of course, scores of music.

${ }^{34}$ Martin-Löf (1987) discusses the significance of this fact. §5.4).

See Prawitz (1971, $\S 3.3-3.5)$, Dummett (1977, Ch. 4), or Tennant $(1978, \S 4.10$,

${ }^{36}$ For further information concerning this truth-maker perspective on the correspondence theory of truth, see Mulligan, Simons and Smith (1984). I have spelled out some consequences of adopting this perspective to the constructive notion of truth in my (1994).

${ }^{37}$ For which regress, see my (1983, p. 162).

${ }^{38} \mathrm{I}$ have dealt with this notion at some length in (1994a).

${ }^{39}$ Brentano $(1956, \S 27)$.

${ }^{40}$ Brentano $(1956, \S 30)$. These reductions were known also to Leibniz and to Bolzano. Bolzano, however, used his standard form of judgement $\mathrm{A}$ is true, and the reductions in terms of the Gegenständlichkeit einer Vorstellung (exemplification of a concept) were carried out in the Sätze an sich (propositions) that serve as contents of his judgements.

${ }^{41}$ All "empty" propositions, that is, propositions with no proof-objects are (materially) equivalent (while false), but they need not be logically equivalent, nor are they identical propositions. For instance, the (sets of proofs of the) propositions $\perp$ and $A \& \neg A$ are both empty. (In this, and some subsequent examples, I find it convenient to identify the proposition A and the set proof(A), so as not to overburden the notational patience of the reader.) The propositions are not identical, though. For the propositions A and B to be identical the inferences from the judgement $a \in A$ to the judgement $a \in B$ (where $a$ is canonical), and conversely, must be immediate from the meaning explanations of the propositions in question. In the example just given, by stipulation $\perp$ has no canonical proofs, whereas a canonical proof of $\mathrm{A} \& \neg \mathrm{A}$ has to be an ordered pair $<\mathrm{a}, \mathrm{b}>$ the first component a of which is a proof of $\mathrm{A}$ and the second component $\mathrm{b}$ is a proof of $\neg \mathrm{A}$. Clearly, then, these are not identical propositions. Applying the proof object $b$ to a one obtains $a p(b, a) \in \perp$, which is impossible since, according to its meaning explanation, $\perp$ has no canonical proofs (and so no proofs at all). For more discussion, see my (1994b).

${ }^{42}$ For plausibility, and feasibility, the numbers considered should be taken below, say, 10 000 .

${ }^{43}$ Brentano $(1930$, p. 139) and $(1956, \S 42)$. Note how the standard regress arguments (Dialelle), e. g. Kant (1800, Ch. VII) and Frege $(1918$, p. 60), against the correspondence theory are obviated here by letting the judgement correspond to another judgement.

${ }^{44}$ Brentano (1956, §35, p. 143). (My) English translation:

Error is precluded with evidence. Also doubt is precluded with evidence, but the judgement is not made evident by freedom from error, or by freedom from doubt, but by a peculiarity that characterizes it as correct.

${ }^{45} W L \S 34,3$, a: 'Jedes Urteil enthält einen Satz, der entweder der Wahrheit gemäss ist oder ihr nicht gemäss ist; und in dem ersten Falle heisset das Urteil ein richtiges, im zweiten ein unrichtiges.' $W L \S 36$ : (Bolzano) 'versteht unter dem Worte Erkenntnis ein jedes Urteil, das einem wahren Satz enthält.'

${ }^{46}$ Thus Socrates in Plato's Republic, 506c. I am indebted to Per Martin-Löf for drawing my attention to this splendid passage.

${ }^{47}$ Frege is the only prominent exception to this almost universal acceptance of the Bolzano-reduction of the validity of an inference between statements to the logical holding of 
a matching consequence-relation between the propositional contents of the statements in question, cf. Currie (1987).

${ }^{48}$ I discuss this notion of validity, and its roots in medieval logic, in my (1998) and (1998a).

${ }^{49}$ (1972, p. 275, fn. h).

${ }^{50}$ (1963, p. 10). (On my reading Curry conflates proofs as acts and proofs as objects.) The final part of the quote attempts to find a place within constructivism for the effects of Gödel's incompleteness theorem. Martin-Löf (1994) gives an account of Gödel incompleteness for the constructivist framework, and some details can be found in section 8 below.

${ }^{51}$ See section 1 above.

52 This section draws heavily on Martin-Löf (1994), and in some measure also on Sundholm (1990), (forthcoming).

${ }^{53}$ Summa contra Gentiles, Ch. X, and Summa Theologica, QII.1, respectively, K.d.r.V. B6.

${ }^{54} \mathrm{I}$ am not unaware that several Quinean (1951) bullets are being bitten here.

${ }^{55}$ 6.113. Wittgenstein's formulation - am Symbol allein - recalls the scholastic ex vi terminorum (or ex terminis). (See footnote 10 above.) In my (1990) the analogy is noted between

(i) Kant

(ii) Wittgenstein

(iii) Martin-Löf

The judgement $\mathrm{S}$ is $\mathrm{P}$ is analytic, that is, the predicate $\mathrm{P}$ is contained in the concept of the subject $S$ $\mathrm{P}$ is a formal (or internal) property (feature) of a

${ }^{56}$ Indeed, the notion of judgement as such gets very short shift in the Tractatus; in 4.442 Frege's Urteilsstrich - in fact the combination of the Urteils- and Inhalts-striche - is dismissed as being entirely without logical significance.

${ }^{57}$ Tractaus 4.46 , respectively, WL $\$ 148(3)$.

${ }^{58} 6.11,6.113$.

596.1203 .

${ }^{60}$ Formal theories in so called standard first order fomalization are, from the present meaning-theoretical perspective, obtained by the step from $S$ to $S_{\text {PROp. }}$. In the process of jettisoning the proof-objects much information is lost. For certain purposes, this is of no consequence. Sometimes, however, unwanted phenomena arise, such as in case of the Gödel theorem, where a conservative extension including proof-objects, is changed into a nonconservative extension by suppressing them.

${ }^{61} 5.1363,5.4731,6.1271$.

\section{REFERENCES}

Bolzano, B.: 1837, Wissenschaftslehre, J. von Seidel, Sulzbach.

Brentano, F.: 1930 (1974 II), Wahrheit und Evidenz, O. Kraus (ed.), Felix Meiner Verlag, Hamburg.

Brentano, F.: 1956, Die Lehre vom richtigen Urteil, F. Mayer-Hildebrand (ed.), A. Francke Verlag, Bern.

Brouwer, L. E. J.: 1908, 'De onbetrouwbaarheid der logische principes', Tijdschrift voor Wijsbegeerte 2, 152-158.

Church, A.: 'A note on the Entscheidungsproblem', Journal of Symbolic Logic 1, 40-41, corrections 101-102. 
Currie, G.: 1987, 'Remarks on Frege's Conception of Inference', Notre Dame Journal of Formal Logic 28, 53-68.

Curry, H. B.: $1976\left(1963^{I}\right)$, Foundations of Mathematical Logic, Dover Pub., New York.

Diller, J. and A. Troelstra: 1984, 'Realizability and intuitionistic logic', Synthese 60, 253-282.

Dubislav, W.: $1931^{\mathrm{III}}\left(1981^{\mathrm{IV}}\right)$, Die Definition, Felix Meiner Verlag, Hamburg.

Dummett, M.: 1977, Elements of Intuitionism, Oxford U. P.

Dummett, M.: 1978, Truth and Other Enigmas, Duckworth, London.

Dummett, M.: 1991, The Logical Basis of Metaphysics, Duckworth, London.

Dummett, M.: 1993, The Seas of Language, Duckworth, London.

Duns Scotus, J.: 1987, Philosophical Writings, A. Wolter and O. F. M. (eds.), Hackett Pub., Indianapolis.

Fichte, G.: 1797, 'Erste Einleitung in die Wissenschaftslehre', Philosophisches Journal 5, 147.

Franchella, M.: 1994, 'Heyting's Contribution to the Change in Research into the Foundations of Mathematics', History and Philosophy of Logic 15, 149-172.

Frege, G.: 1892, 'Über Sinn und Bedeutung', Zeitschrift für Philsophie und philosophische Kritik 100, 25-50.

Frege, G.: 1893, 1903, Grundgesetze der Arithmetik, Band I, Band II, H. Pohle, Jena.

Frege, G.: 1918, 'Der Gedanke', Beiträge zur Philosophie des deutschen Idealismus 2, 58-77.

Gödel, K.: 1931, UUber formal unentscheidbare Sätze der Principia mathematica und verwandter Systeme I', Monatshefte für Matematik und Physik 38, 173-198.

Gödel, K.: 1944, 'Russell's mathematical logic', in P. A. Schilpp (ed.), The Philosophy of Bertrand Russell, Library of Living Philosophers, Evanston, pp. 123-153 and in Gödel, 1990, pp. 119-143.

Gödel, K.: 1972, 'On an extension of finitary mathematics which have not yet been used', in Gödel, 1990, pp. 271-280.

Gödel, K.: 1990, Collected Works, Vol. II, Oxford U. P., New York.

Goldfarb, W.: 'Logic in the twenties: the nature of the quantifier', Journal of Symbolic Logic 44, 1979, 351-368.

Hale, B.: 1997, 'Realism and its oppositions', in B. Hale and C. Wright, A Companion to the Philosophy of Language, Blackwell, Oxford, pp. 271-308.

Heyting, A.: 1930, 'Die formalen Regeln der intuitionistischen Logik', Sitzungsberichte der preussischen Akademie von Wissenschaften, Phys.-math. Klasse, pp. 42-56. English translation in P. Mancosu (ed.), From Brouwer to Hilbert, Oxford U. P., 1997, pp. 311327.

Heyting, A.: 1930a, 'Sur la logique intuitionniste', Acad. Roy. Belgique, Bull. Cl. Sci., V, 16, 957-963; English translation in P. Mancosu (ed.), From Brouwer to Hilbert, Oxford U. P., 1997, pp. 306-310.

Heyting, A.: 1931, 'Die intuitionistische Grundlegung der Mathematik', Erkenntnis 2, pp. 106-115. English translation in P. Benacerraf and H. Putnam, Philosophy of Mathematics (second edition), Cambridge U. P., Cambridge, 1983, pp. 52-61.

Heyting, A.:1934, Mathematische Grundlagenforschung. Intuitionismus. Beweistheorie, Julius Springer, Berlin.

Heyting, A.: 1958, 'Intuitionism in mathematics', in Raymond Klibanski (ed.), Philosophy in the Mid-Century, La nouva editrice, Florence, pp. 101-115.

Hintikka, J.: 1988, 'On the development of the model-theoretic viewpoint in logical theory', Synthese 77, 1-36.

Hintikka, J.: 1996, Lingua Universalis vs. Calculus Ratiocinator: An Ultimate Presupposition of Twentieth-Century Philosophy, Kluwer, Dordrecht. 
Howard, W.: 1969, 'The fomulae-as-types notion of construction', in Seldin, Jonathan, and Roger Hindley (eds.), To H. B. Curry: Essays on Combinatory Logic, Lambda Calculus and Formalism, Academic Press, London, 1980, pp. 479-490.

Kant, I.: $1800\left(1904^{\mathrm{III}}\right)$, Logik, B. Jäsche (ed.), Felix Meiner Verlag, Leipzig.

Kolmogoroff, A. N.: 1932, 'Zur Deutung der intuitionistichen Logik', Mathematische Zeitschrift 35 (1932), 58-65; English translation in P. Mancosu (ed.), From Brouwer to Hilbert, Oxford U. P., 1997, pp. 328-334.

Martin-Löf, P.: 1984, Intuitionistic Type Theory, Bibliopolis, Naples.

Martin-Löf, P.: 1985, 'On the meanings of the logical constants and the justifications of the logical laws', in Nordic Journal of Philosophical Logic 1 (1996), 11-60; originally delivered in 1983 and published in 1985; electronically available at http://www.hf.uio.no/filosofi/njpl/.

Martin-Löf, P.: 1987, 'Truth of a proposition, evidence of judgement, validity of a proof', Synthese 73, 191-212.

Martin-Löf, P.: 1994, 'Analytic and synthetic judgements in type theory', in P. Parrini (ed.), Kant and Contemporary Epistemology, Kluwer, Dordrecht, pp. 87-99.

Martin-Lö, P.: 1995, 'Verificationism then and now', in Schimanovich, W. De Pauli, E. Köhler, and F. Stadler (eds.), The Foundational Debate: Complexity and Constructivity in Mathematics and Physics, Kluwer, Dordrecht, pp. 187-196.

Martin-Löf, P.: 1998, 'Truth and knowability: on the principles C and $\mathrm{K}$ of Michael Dummett', in H. G. Dales and G. Oliveri (eds.), Truth in Mathematics, Clarendon Press, Oxford.

Mulligan, K., P. Simons, and B. Smith: 1984, 'Truth-Makers', Philosophy and Phenomenological Research 44, 287-321.

Niniluoto, I.: 1997, 'Tarskian truth as correspondence - replies to some objections', in J. Peregrin (ed.), The Nature of Truth (If Any). Proceedings of the International Colloquium, Prague, September 17-20, 1996, Filosofia, Prague, 1997, pp. 153-160.

Olson, R. G.: 1967, 'Nihilism', in P. Edwards (ed.), The Encyclopaedia of Philosophy, Macmillan, New, York.

Patzig, G.: 1971, 'Kritische Bemerkungen zu Husserls thesen über das Verhältnis von Wahrheit und Evidenz', Neue Hefie für Philosophie, Heft 1, Vandenbroek und Rupprecht, Göttingen, 12-32; translated into English by J. N. Mohanty as 'Husserl on truth and evidence', in J. N. Mohanty (ed.), Readings on Husserl's Logical Investigations, Nijhoff, The Hague, 1977, pp. 179- 196.

Prawitz, D.: 1971, 'Ideas and results in proof theory', in J. E. Fenstad, Proceedings of the Second Scandinavian Logic Symposium, Amsterdam, North-Holland, pp. 235-307.

Putnam, H.: 1981, Realism and Reason, Cambridge U. P., Cambridge.

Quine, W. V. O.: 1951, 'Two dogmas of empiricism', reprinted in From a Logical Point of View, Harper \& Row, N. Y., 1961 II , pp. 20-46.

Ramsey, F. P.: 1925, 'The foundations of mathematics', Proceedings of the Aristotelian Society 25, 338-384.

Rogers, Jr., H.: 1967, Theory of Recursive Functions and Effective Computability, McGrawHill Book Company, New York.

Schlick, M.: 1910-11, 'Das Wesen der Wahrheit nach der modernen Logik', Vierteljahrschrift für wissenschaftliche Philosophie und Soziologie 34-35, 386-477; reprinted in M. Schlick, Philosophische Logik, B. Philippi (ed.), Suhrkamp Taschenbuch, 1986.

Stegmüller, W.: 1954, Metaphysik, Wissenschaft, Skepsis, Humboldt-Verlag, Vienna.

Sundholm, G.: 1983, 'Constructions, proofs and the meaning of the logical constants', Journal of Philosophical Logic 12, 151-172. 
Sundholm, G.: 1987, 'Proof theory and meaning', in D. Gabbay and F. Guenthner, Handbook of Philosophical Logic, Vol. III, Reidel, Kluwer, pp. 471-506.

Sundholm, G.:, 1990, 'Sätze der Logik: an Alternative Conception', in R. Haller and J. Brandl (eds.), Wittgenstein - Towards a Re-Evaluation. Prroceedings of the 14th International Wittgenstein-Symposium Centenary Celebration, Verlag Hölder-Pichler-Tempsky, Wien, pp. 59-61.

Sundholm, G.: 1993, 'Questions of Proof', Manuscrito (Campinas, S. P.), 16, pp. 47-70.

Sundholm, G.: 1994, 'Ontologic versus epistemologic', in D. Prawitz and D. Westerståhl (eds.), Logic and Philosophy of Science in Uppsala, Kluwer, Dordrecht, pp. 373-384.

Sundholm, G.: 1994a, 'Existence, proof and truth-making: a perspective on the intuitionistic conception of truth', TOPOI 13, 117-126.

Sundholm, G.: 1994b, 'Proof-theoretical semantics and Fregean identity criteria for propositions', The Monist 77, 294-314.

Sundholm, G.: 1997, 'Implicit epistemic aspects of constructive logic', Journal of Logic, Language, and Information 6, 191-212.

Sundholm, G.: 1998, 'Inference, Consequence, Implication', Philsophia Mathematica 6, 178 194.

Sundholm, G.: 1998a, 'Inference versus Consequence', in Logica Yearbook 1997 (T. Childers, ed.), Philsophia Publ., Czech Academy of Science, Prague, pp. 26-35.

Sundholm, G., forthcoming: 'Proofs as Acts versus Proofs as Objects: Some Questions for Dag Prawitz', to appear in a special issue of Theoria dedicated to the work of Dag Prawitz.

Tarski, A.: 1936, 'Über den Begriff der logischen Folgerung', Act. Congr. Phil. Sci. (Paris), VII, Actualités Scientifiques et Industrielle 394, 1-11.

Tarski, A. and R. Vaught, 'Arithmetical Extensions of Relational Systems', Compositio Matematica 13, 81-102.

Tennant, N.: 1987, Anti-Realism and Logic, Clarendon Press, Oxford.

Tennant, N.: 1997, The Taming of the True, Clarendon Press, Oxford.

Thiel, C., 1988, 'Die Kontroverse um die intuitionistische Logik vor ihre Axiomatisierung durch Heyting im Jahre 1930', History and Philosophy of Logic 9, 67-75.

van Heijenoort, J.: 1967, 'Logic as calculus versus logic as language', Synthese 17, 324-330.

van Heijenoort, J.: 1976, 'Set-theoretic semantics', in R. O. Gandy and M. Hyland (eds.), Logic Colloqium '76, North-Holland, Amsterdam, pp. 183-190.

Vier, P. C.: 1951, Evidence and its Function According to John Duns Scotus, The Franciscan Institute, St. Bonaventure, N.Y.

Weyl, H.: 1921, 'Über die neue Grundlagenkrise der Mathematik', Mathematische Zeitschrift 10, 37-79; English translation in P. Mancosu, From Brouwer to Hilbert, Oxford U. P., 1997, pp. 86-118.

Wiggins, D.: 1980, 'What would be a substantial theory of truth?', in Z. van Straaten, Philosophical Subjects: Essays Presented to P. F. Strawson, Clarendon, Oxford, pp. 189221.

Wiggins, D.: 1992, 'Meaning, truth-conditions, proposition: Frege's doctrine of sense retrieved, resumed and redeployed in the light of certain recent criticisms', Dialectica 46, $61-90$.

Wiggins, D.: 1997, 'Meaning and truth-conditions: from Frege's grand design to Davidson's', in B. Hale and C. Wright (eds.), A Companion to the Philosophy of Language, Blackwell, Oxford, pp. 271-308.

Wittgenstein, L.: 1922, Tractatus Logico-Philosophicus, Routledge and Kegan Paul, London. 